\title{
Association between body composition and khat chewing in Ethiopian adults
}

Tsinuel Girma ${ }^{1 * \dagger}$, Andualem Mossie ${ }^{2+}$ and Yesufe Getu ${ }^{3+}$

\begin{abstract}
Background: Khat (Catha edulis Forsk) is a psychostimulant herb widely cultivated and used in Ethiopia. The link between khat use and body composition is little known.

Objective: The aim was to determine the association between body composition and khat use.

Methods: We recruited 415 individuals 18-78 years of age from Jimma Town. Sociodemographic and lifestyle data were collected using structured questionnaires. Fat mass (FM, kg) and fat-free mass (FFM, $\mathrm{kg}$ ) were estimated from whole-body bio impedance. Weight ( $\mathrm{kg})$, FM and FFM were indexed to height $(\mathrm{m})$ as BMI $\left(\mathrm{kg} / \mathrm{m}^{2}\right)$, fat mass index (FMI) $(\mathrm{kg} / \mathrm{m})$ and fat-free mass index (FFMI) $(\mathrm{kg} / \mathrm{m})$, respectively. Independent predictors of BMI, FMI and FFMI were identified using regression analysis.

Result: Participants' mean \pm SD of age was $37 \pm 13$ years and 205 (53.2\%) were males. Mean \pm SD of BMl, FMl and FFMI were $21.0 \mathrm{~kg} / \mathrm{m}^{2} \pm 4.1,6.8 \mathrm{~kg} / \mathrm{m} \pm 5.2$ and $27.9 \mathrm{~kg} / \mathrm{m} \pm 3.8$, respectively. Multivariable model showed that, compared with non-chewers, khat chewers had a lower $\mathrm{BMI}(\mathrm{B}=-1.56,95 \% \mathrm{Cl}-0.78,-2.33)$ and $\mathrm{FMI}(\mathrm{B}=2.19,95 \% \mathrm{Cl}$ $-1.32,-3.06)$. FMI was lower in cigarette smokers than non-smokers by $-1.36 \mathrm{~kg} / \mathrm{m}(95 \% \mathrm{Cl}-0.23,-2.49)$. Concurrently, khat and cigarette users increased FMI by $2.78(95 \% \mathrm{Cl} 0.11,5.44)$. FFMl decreased with age $(\mathrm{B}=-0.02,95 \% \mathrm{Cl}$ $-0.05,-0.002)$.
\end{abstract}

Conclusion: FMI and BMI were lower in khat users than non-users, but there was no difference in lean mass. The consequence of this body composition change should be investigated.

Keywords: Body composition, Khat chewing, Fat mass, Fat free mass, Bioimpedance, Catha edulis Forsk

\section{Background}

The psychostimulant herbal plant, khat (Catha edulis Forsk) is produced abundantly in East Africa and the habit of chewing khat leaves among certain populations of Ethiopia dates back centuries [1]. Fresh khat leaves and young buds are usually chewed to obtain a state of euphoria [2]. Khat contains the active chemicals cathinone and cathine, which have a structural and functional resemblance to amphetamine and share many pharmacologic features in common [3]. Khat has various physiologic and metabolic effects associated with a decrease in

\footnotetext{
*Correspondence: tsinuel@yahoo.com

${ }^{\dagger}$ Yesufe Getu, Andualem Mossie and Tsinuel Girma contributed equally ${ }^{1}$ Department of Paediatrics and Child Health, College of Public Health and Medical Sciences, Jimma University, Jimma, Ethiopia Full list of author information is available at the end of the article
}

appetite and body weight, possibly mediated via increasing the release of leptin from the stomach [4].

Khat chewing and its impact on elevated plasma leptin, esterified fatty acid production and resulting lipodystrophy, which leads to further problems on the cardiovascular system, urinary system, gastrointestinal tract, spermatogenesis, and impotence and loss of appetite have been summarised in previous studies [5, 6]. Previous studies used weight measurement to assess the effect of khat chewing on the body [6]. However, data on the effect of khat on the different constituents of body mass i.e. body composition are lacking.

Body composition is a term used to describe the different constituents that make up a human's body weight. According to elemental, chemical, anatomical or fluid components, body composition investigation involves subdividing body weight into two or more compartments. 
The classic two-compartment model divides the body mass into fat mass (FM) and fat-free mass (FFM) compartments. The FM comprises of all lipids, and the FFM includes water, protein, and mineral components [7].

There are several different methods used to identify body composition, such as body mass index, skin folds and bioelectrical impedance analyses [8]. Bioelectrical Impedance Analysis (BIA) is an easy, cheap, valid and non-invasive method, in which resistance to a low electric current level with a frequency of $50 \mathrm{kHz}$ is proportional to the percentage of FM [8]. The BIA technique considers a two-compartment model based on the principle that an electrical current flows more rapidly through tissues with higher water and electrolyte content than through fatty tissues, which are dehydrated.

Khat is produced in Jimma area in abundance and many people in the region use it for mood elevation. Based on simple observation, khat users are physically tiny and bony, probably because chemicals in khat may suppress their appetite. There are only limited data documented so far about the association between khat use and body composition. Moreover, the current study is the first of its type to determine body composition using BIA to measure FM and FFM among khat users and nonusers. Therefore, the main aim of the present study was to determine the association between body composition and khat use by measuring the actual FM and FFM, helping fill the current gap in knowledge.

\section{Methods}

The study was conducted in Jimma town, Ethiopia, from February 1 to March 30, 2012. The total projected population of the town from 2007 central statistical agency (CSA) census report was 120, 960 [9]. Individuals aged 18 and above living in Jimma town were used as the source population. Pregnant women or lactating mothers with babies under 6 months, physical disability, clients with history of chronic illness such as HIV/AIDS and diabetes mellitus were excluded.

The sample size was calculated using single population proportion formula, assuming a confidence level of 95 and $10 \%$ allowance for non-response rate. The proportion of overweight $(\mathrm{P})$ plus obesity, which is $43.3 \%$ (Over weight $=24.1 \%$ and obesity $=19.2 \%)$ taken from studies done in Tanzania [10].

Multistage simple random sampling technique was employed to select the study participants. Six kebeles (the smallest administrative unit of Ethiopia) were selected from a total of 13 kebeles found in the town by a lottery method. The potential sample size was allocated to each study kebele by population proportion. Urban health extension workers (UHEW) invited adults from their respective kebeles to participate in the study.
Participants who fulfilled the inclusion criteria were selected for interview, anthropometric and body composition measurement.

The data collection was done at six sites, i.e. in the office of urban health extension workers in each study kebeles. Five well trained nurses were involved in the data collection activities under strict supervision by the investigators.

Data on sociodemographic and lifestyle habits such as khat chewing, alcohol drinking, cigarette smoking and level of physical activity were obtained from a pre-tested interviewer-administered structured questionnaire. The WHO stepwise approach for chronic disease risk factor surveillance in developing countries was used with certain modifications [11].

Physical activity level was assessed based on selfreported physical commotion of participants for the period of work. "Physically active" was defined as a person doing activities that require hard physical effort and cause large increases in breathing or heart rate (like carrying or lifting heavy loads, digging or construction work) for at least 10 min continuously within a day such as crop harvesting, fishing and hunting. "Physically inactive" was defined as a person doing activities that require smaller physical effort and causes small increases in breathing or heart rate like brisk walking, carrying light loads. "Current khat chewer" was defined as khat chewing at least once in the past 30 days.

Weight was measured with subjects minimally dressed and barefoot (TANITA, BC-418MA model) and recorded at a precision of $0.1 \mathrm{~kg}$. Height was measured using a height measurement board of clients in upright position with barefoot at a precision of $0.1 \mathrm{~cm} \mathrm{[12].} \mathrm{Waist} \mathrm{circum-}$ ference was measured in triplicates using non-elastic measuring tape midway between the inferior margin of the last rib and the iliac crest at the end of expiration [13] and the mean was calculated for analysis. The tape was first calibrated by a ruler.

Whole-body bioimpedance was measured using bioimpedance analyser (TANITA Corporation, Tokyo, Japan), and according to a protocol by the manufacturer [14]. Age, sex and height of the individuals were fed into the analyser and estimates of FFM $(\mathrm{kg})$, FM $(\mathrm{kg})$ and body mass index $\left(\mathrm{BMI}, \mathrm{kg} / \mathrm{m}^{2}\right)$ generated by the machine were recorded. FM and FFM were indexed for height as FMI and FFMI during analysis. Body fat percentage $>25 \%$ for males and $>33 \%$ for females were used as a cut-point for excess body fat (EBF) [15].

Data was double entered into EpiData (Odense, Denmark) and analyzed using Stata 12 (StataCorp LP, College station, Texas, USA). The mean differences in continuous outcomes between groups were tested using the student's $t$ test with $\mathrm{p} \leq 0.05$ considered to be significant. 
Hierarchical multiple linear regression analysis was employed to find independent predictors of the outcome variable. The following covariates were included in the regression model: Age, sex, ethnicity, religion, marital status, educational status, monthly income, cigarette smoking, alcohol drinking, and physical activity. We used interaction term in the model to test if gender, cigarette smoking, alcohol drinking moderated the link between khat use and body composition measures.

Ethical clearance for the study was obtained from an Ethical Review Board of Jimma University. Client's written consent was taken and confidentiality was maintained. For those illiterates, we took their fingerprint as a signature.

\section{Results}

We studied 415 participants. All data from 30 (7.2 \%) of them were excluded because of incompleteness. The mean \pm SD of age of the participants was $37 \pm 13$ years and $205(53.2 \%)$ of them were males (Table 1). Among the participants, $226(58.7 \%)$ and 186 (48.3\%) were from the Oromo ethnic group and Muslims, respectively.

Table 1 Selected sociodemographic characteristics of the study participants $(\mathbf{N}=\mathbf{3 8 5})$

\begin{tabular}{|c|c|c|}
\hline Sociodemographic variables & Categories & N (\%) \\
\hline Age, year & mean $\pm S D$ & $37 \pm 13$ \\
\hline Sex & Male & $205(53.2)$ \\
\hline \multirow[t]{6}{*}{ Ethnicity } & Oromo & $226(58.7)$ \\
\hline & Amhara & $63(16.4)$ \\
\hline & Gurage & $27(7.0)$ \\
\hline & Dawuro & $23(6.0)$ \\
\hline & Tigrie & $18(4.7)$ \\
\hline & Others $^{a}$ & $28(7.3)$ \\
\hline \multirow[t]{4}{*}{ Religion } & Muslim & $186(48.3)$ \\
\hline & Orthodox & $148(38.4)$ \\
\hline & Protestant & $44(11.4)$ \\
\hline & Catholic & $7(1.8)$ \\
\hline \multirow[t]{4}{*}{ Marital status } & Married & $263(68.3)$ \\
\hline & Single & $72(18.7)$ \\
\hline & Divorced & $37(9.6)$ \\
\hline & Widowed & $13(3.4)$ \\
\hline \multirow[t]{4}{*}{ Educational status } & Illiterates & $40(10.4)$ \\
\hline & Primary school & $164(42.6)$ \\
\hline & Secondary school & $96(24.9)$ \\
\hline & Tertiary & $85(22.1)$ \\
\hline \multirow[t]{3}{*}{ Family monthly income, Birr } & $<1000$ & $85(22.1)$ \\
\hline & $1000-2000$ & $138(35.8)$ \\
\hline & $>2000$ & $162(42.1)$ \\
\hline
\end{tabular}

19.31 Birr = 1USD

a Kefficho, Yem, Selte
The proportions of those with history of ever chewing Khat, ever smoking cigarettes and ever drinking alcohol were $186(48.3 \%), 60$ (15.3\%) and 185 (48.1\%), respectively (Table 2).

Compared with non-khat chewers, chewers had a lower waist circumference [Diff $=-3.6 \mathrm{~cm}, 95 \%$ CI $([-5.8,-1.4])$, df. $=383(\mathrm{t}=12.0, \mathrm{p}<0.001)$, BMI $\left[\right.$ Diff $\left.=-5.9 \mathrm{~kg} / \mathrm{m}^{2}, 95 \% \mathrm{CI}([-8.2,-3.6])\right], \mathrm{df} .=383$ $(\mathrm{t}=7.6, \mathrm{p}<0.001)$, fat mass [Diff $=-7.9 \mathrm{~kg}, 95 \% \mathrm{CI}$ $([-9.4,-6.4])]$, df. $=383(\mathrm{t}=12.0, \mathrm{p}<0.001)$ and trunk fat mass [Diff $=-3.8 \mathrm{~kg}, 95 \% \mathrm{CI}([-4.6,-3.0])]$, df. $=383,(\mathrm{t}=-6.28, \mathrm{p}<0.001)$ of (Table 3$)$. Whereas FFMI of khat chewers was higher than that of the nonchewers, [Diff $=1.7 \mathrm{~kg} / \mathrm{m}, 95 \%$ CI $([1.0,2.4])], \mathrm{df} .=383$, $(\mathrm{t}=4.56, \mathrm{p}<0.001)$.

As shown in Table 4, an inverse relationship was observed between the frequency of khat chewing and the percentage of individuals having EBF $(p=0.005)$. Similarly, the proportion of individuals with EBF was lower among those who chewed khat for two or more years compared with chewing for shorter duration (8.1 vs. $20.3 \%, \mathrm{p}=0.04)$.

Table 2 Substance use profile of 385 Ethiopian adults

\begin{tabular}{lr}
\hline & n (\%) \\
\hline Ever chew khat & $186(48.3)$ \\
Current khat chewing & $138(35.8)$ \\
Ever smoke cigarette & $60(15.3)$ \\
Current cigarette smoking & $43(11.2)$ \\
Ever drink alcohol & $185(48.1)$ \\
Current alcohol drinking & $167(43.4)$ \\
\hline
\end{tabular}

Table 3 Association of body composition estimated from whole-body bioimpedance and khat chewing in $\mathbf{3 8 5}$ Ethiopian adults

\begin{tabular}{|c|c|c|c|c|}
\hline & \multicolumn{2}{|c|}{ Current khat chewing $^{a}$} & \multirow[t]{2}{*}{ Diff $[95 \% \mathrm{Cl}]$} & \multirow[t]{2}{*}{ p-value } \\
\hline & Yes $(n=138)$ & No $(n=247)$ & & \\
\hline Weight (kg) & $55.8(10.1)$ & $59.5(12.0)$ & $-3.6[-5.8,-1.4]$ & $<0.001$ \\
\hline $\begin{array}{l}\text { Waist circumfer- } \\
\text { ence }(\mathrm{cm})\end{array}$ & $77.7(10.2)$ & $83.6(12.4)$ & $-5.9[-8.2,-3.6]$ & $<0.001$ \\
\hline $\begin{array}{l}\text { Body mass index } \\
\qquad\left(\mathrm{kg} / \mathrm{m}^{2}\right)\end{array}$ & $19.7(3.0)$ & $22.3(4.3)$ & $-2.6[-3.4,-1.9]$ & $<0.001$ \\
\hline Fat mass (kg) & $7.1(5.8)$ & $15.0(8.6)$ & $-7.9[-9.4,-6.4]$ & $<0.001$ \\
\hline $\begin{array}{l}\text { Fat mass index } \\
\qquad(\mathrm{kg} / \mathrm{m})\end{array}$ & $4.3(3.4)$ & $9.2(5.3)$ & $-5.0[-5.9,-4.1]$ & $<0.001$ \\
\hline Fat free mass (kg) & $48.7(8.2)$ & $44.4(7.1)$ & $4.3[2.7,5.8]$ & $<0.001$ \\
\hline $\begin{array}{l}\text { Fat free mass } \\
\text { index }(\mathrm{kg} / \mathrm{m})\end{array}$ & $28.8(3.9)$ & $27.1(3.4)$ & $1.7[1.0,2.4]$ & $<0.001$ \\
\hline $\begin{array}{l}\text { Trunk fat } \\
\text { mass (kg) }\end{array}$ & $3.5(3.2)$ & $7.3(4.8)$ & $-3.8[-4.6,-3.0]$ & $<0.001$ \\
\hline
\end{tabular}

a Values are given as mean \pm standard deviation and difference between groups was tested with independent sample t-test 
Table 4 Association of the frequency and duration of khat chewing with excess body fat estimated from whole-body bioimpedance among 385 Ethiopian adults

\begin{tabular}{|c|c|c|c|c|}
\hline & \multicolumn{2}{|c|}{ Excess body fat $(\mathrm{n} \%)^{a}$} & \multirow[t]{2}{*}{$x^{2}$} & \multirow[t]{2}{*}{ P-value } \\
\hline & Yes & No & & \\
\hline \multicolumn{5}{|l|}{ Khat chewing status } \\
\hline None chewers & $73(36.7)$ & $126(63.3)$ & 13.3 & 0.01 \\
\hline Ex-chewers & $15(29.2)$ & $34(70.8)$ & & \\
\hline Current chewers & $25(18.2)$ & $118(81.8)$ & & \\
\hline \multicolumn{5}{|c|}{ Frequency of chewing } \\
\hline Every day & $4(12.1)$ & 29 (87.9) & 12.6 & 0.005 \\
\hline 2-3 days/week & $5(12.5)$ & $35(87.5)$ & & \\
\hline Once a week & $5(12.8)$ & $34(87.2)$ & & \\
\hline Occasionally & $11(43.3)$ & $15(57.7)$ & & \\
\hline \multicolumn{5}{|c|}{ Duration of chewing } \\
\hline$<2$ year & $13(20.3)$ & $51(79.7)$ & 4.3 & 0.04 \\
\hline$\geq 2$ year & $6(8.1)$ & $68(91.9)$ & & \\
\hline
\end{tabular}

a Body fat was; excess body fat $=$ body fat percentage $>25.0 \%$ for males and $>33.0 \%$ for females

In the multiple regression model (Table 5), BMI increased with age (Beta, B) $=0.03,95 \%$ CI 0.00, 0.057) and monthly income $(\mathrm{B}=0.002,95 \% \mathrm{CI} 0.001,0.003)$. Similarly FMI increased with age $(B=0.06,95 \%$ CI 0.03 , 0.09), monthly income ( $\beta=0.002,95 \%$ CI $0.002,0.003)$, with lesser physical activity level $(B=0.94,95 \%$ CI 0.09 , $1.80)$ and was higher in females than males by $3.12(95 \%$ CI 2.25, 3.99). On the other hand, khat chewers had a lower BMI ( $\mathrm{B}=-1.56,95 \% \mathrm{CI}-0.78,-2.33)$. The interaction term discovered that using both khat and cigarette increased FMI by 2.78 (95\% CI 0.11, 5.44). FFMI decreased with age $(\mathrm{B}=-0.02,95 \% \mathrm{CI}-0.05,-0.002)$ and was lower in females than males by -4.66 (95\% CI $-5.26,-4.05)$.

\section{Discussion}

Our study revealed major findings, i.e. khat chewers were lighter and less-fatter than non-chewers whereas no relationship was found between khat chewing and FFMI. Moreover, older individuals and females, compared with males, were fatter and had a lesser lean body mass. Cigarette smoking was negatively related with FMI.

A decrease in FMI and BMI among khat chewers may be due to a decrease in food intake as a result of appetite suppressant effects of khat [16]. Khat contains active ingredients called cathinone and cathine, which are amphetamine-like compounds that can inhibit the appetite centre in the hypothalamus [17]. These effects are probably mediated via increasing the level of leptin in plasma and have fat mobilization effect by acting indirectly. Apart from its central effect, cathinone enhances sympathomimetic activity leading to a delay in gastric emptying [18].

On the other hand, individuals who use both khat and cigarette had higher fat mass. This may be related to the potentiating effect of Khat chewing on cigarette smoking. That means khat chewer smokers smoke more cigarette than non-chewer smokers. Therefore, adults who consume both khat and cigarette would have greater smoking profile and have a greater body weight than do light smoker [19].

FMI increased while the FFMI decreased with age, which is in line with study results done in Bulgaria which showed a positive association between age and FM but a decrease in FFM [20]. With age, metabolism slows because of hormonal and enzymatic factors and physical activity decreases [21], which in turn may decrease energy expenditure and result in the accumulation of body fat.

Another important result of the present study was higher FMI among individuals with relatively higher

Table 5 Predictors of body composition estimated from whole-body bioimpedance among 385 Ethiopian adults

\begin{tabular}{|c|c|c|c|c|c|c|}
\hline & $\begin{array}{l}\text { BMI }\left(\mathrm{kg} / \mathrm{m}^{2}\right) \\
\text { B }(95 \% \mathrm{Cl})\end{array}$ & p-value & $\begin{array}{l}\text { FMI (kg/m) } \\
\text { B (95 \% Cl) }\end{array}$ & $p$-value & $\begin{array}{l}\text { FFMI (kg/m) } \\
\text { B (95\% Cl) }\end{array}$ & $p$-value \\
\hline Age, year & $0.03(0.00,0.057)$ & $0.031^{*}$ & $0.06(0.03,0.09)$ & $<0.001^{*}$ & $-0.02(-0.05,-0.002)$ & $0.036^{*}$ \\
\hline Sex, female & $0.52(-0.24,1.28)$ & 0.180 & $3.12(2.25,3.99)$ & $<0.001^{*}$ & $-4.66(-5.26,-4.05)$ & $<0.001^{*}$ \\
\hline Monthly income, Birr & $0.002(0.001,0.003)$ & $<0.001^{*}$ & $0.002(0.002,0.003)$ & $<0.001^{*}$ & $0.001(0.001,0.0013)$ & $<0.001^{*}$ \\
\hline Current khat chewers** & $-1.56(-0.78,-2.33)$ & $<0.001^{*}$ & $-2.19(-1.32,-3.06)$ & $<0.001^{*}$ & $0.09(-0.66,0.82)$ & 0.817 \\
\hline Cigarette smokers & $0.76(-0.25,1.78)$ & 0.141 & $-1.36(-0.23,-2.49)$ & $0.032^{*}$ & $0.40(-0.49,1.29)$ & 0.379 \\
\hline Current khat chewer ${ }^{\# \#, ~ c i g a r e t t e ~ s m o k e r ~}$ & $2.07(-0.34,4.48)$ & 0.09 & $2.78(0.11,5.44)$ & $0.041^{*}$ & $0.09(-2.04,2.22)$ & 0.936 \\
\hline Physical activity level, inactive & $0.60(-0.16,1.37)$ & 0.123 & $0.94(0.09,1.80)$ & $0.021^{*}$ & $0.20(-0.48,0.87)$ & 0.569 \\
\hline
\end{tabular}

All dependent variables were indexed to height $(\mathrm{m})$ as $B M I$ body mass index; FMI fat mass index and FFMI fat free mass index; 19.31 Birr 1 USD, $B$ regression coefficient. Age, sex, ethnicity, religion, marital status, educational status, monthly income, cigarette smoking, alcohol drinking and physical activity were included in the model

* Significant

** Khat chewing at least once in the past 30 days

\#\# Concurrent of khat chewing and smoking cigarette 
income, this agrees with findings in Nigeria [22]. Individuals with higher income are less likely to be engaged in labour demanding physical activities and had a sedentary lifestyle, thus expending less energy. In addition, adults with higher income have a chance to get more and higher calorie diet than low income adults.

Generalization of the finding in this study will be limited as all the participants were recruited from an urban setting. Whilst our findings are still useful to offer comparative analysis within the study population, validated equations would help to compare findings at the global level.

In conclusion, this study demonstrated that older individuals were not only heavier and fatter, but also had a lesser lean mass than young respondents. Despite comparable weight with males, females were fatter and had lesser lean mass. Both khat users and cigarette smokers had less body fat compared with their respective nonusers. But, individuals who use both khat and cigarette had higher fat mass. However, khat use did not affect lean mass. Body fat decreased with an increase in the level of physical activity, though no effect was found on lean mass.

Animal studies are required to confirm the effect of khat on body composition and to define its mechanism. Additionally, it would be valuable to determine the socioeconomic as well as the health consequences of body composition variation due to khat use.

\section{Authors' contributions \\ YG: involved in the preparation of the study design, participated in data col- lection, data entry and data analysis as well as draft manuscript preparation. AM: involved in the research proposal organization, data collection and data analysis and manuscript preparation. TG: has involved in the preparation of the study design, data analysis and manuscript preparation. All the authors read and approved the final manuscript.}

\section{Author details}

${ }^{1}$ Department of Paediatrics and Child Health, College of Public Health and Medical Sciences, Jimma University, Jimma, Ethiopia. ${ }^{2}$ Department of Biomedical Sciences (Physiology), College of Public Health and Medical Sciences, Jimma University, Jimma, Ethiopia. ${ }^{3}$ Save the Children International, Jimma, Ethiopia.

\section{Acknowledgements}

Authors are grateful to Jimma University for its financial support. Due thanks should be given to study participants as well.

\section{Competing interests}

The authors declare that they have no competing interest.

Received: 17 October 2014 Accepted: 19 October 2015 Published online: 14 November 2015

\section{Reference}

1. Cox G, Rampes H. Adverse effects of khat: a review. Adv Psychiat Treat 2003;456-63.

2. AlMotarreb A, Baker K, Broadley KJ. Khat: pharmacological and medical aspects and its social use in Yemen. Phytother Res. 2002;16:403-13.

3. Ishraq DB, Jiri SB. Khat habit and its health effect. A natural amphetamine. Biomed Papers. 2004;148(1):11-5.

4. Al-Dubai W, AL-Habori M, Al-Geiry A. Human khat (Catha edulis) chewers have elevated plasma leptin and nonesterified fatty acids. Nutr Res. 2006;26:632-6.

5. Getahun W, Gedif T, Tesfaye F. Regular Khat (Catha edulis) chewing is associated with elevated diastolic blood pressure among adults in Butajira, Ethiopia: a comparative study. BMC Public Health. 2010;10:390.

6. Walid AD, Molham AH, Ahmed AG. Human khat (Catha edulis) chewers have elevated plasma leptin and nonesterified fatty acids. Nutr Res. 2006;26:632-6.

7. Siri WE. Body composition from fluid spaces and density: analysis of methods. In: Brozek J, Henschel A (editors). Techniques for measuring body composition Washington, DC: National Academy of Sciences. 1961. p. 223-44.

8. Baumgartner RN. Electrical impedance and total body electrical conductivity. In: Roche AF, Heymsfield SB, Lohman TG, editors. Human body composition. Champaign: Human Kinetics; 1996. p. 79-107.

9. Federal Democratic Republic of Ethiopia. Central statistical Authority of Ethiopia. National Statistics. Ethiopia: Addis Ababa; 2005.

10. Grace A, Ferdinand M. Prevalence of obesity and associated risk factors among adults in Kinondonimunicipal district, Dare Salaam Tanzania. BMC Public Health. 2011;11(365):1-7.

11. WHO STEPwise approach to chronic disease risk factor surveillance fact sheet. Ethiopia (Addis Ababa) STEP survey 2006. http://www.who.int/ chp/steps.

12. World Health Organization: Obesity: Preventing and Managing the Global Epidemic. WHO Obesity Technical Report Series 894. Geneva, Switzerland: World Health Organization 2000.

13. Wang Y, Beydoun M. The obesity epidemic in the United States gender, age, socioeconomic, racial/ethnic, and geographic characteristics: a systematic review and meta-regression analysis. Epidemiology. 2007;29:6-28.

14. Body composition analyzer BC-418MA instruction manual, 2002.

15. Bray GA. Who are the obese? Body composition and prevalence. Contemporary diagnosis and management of obesity. Newton: Handbooks in Health Care; 1998. p. 9-34

16. Sonia AT. Phytochemicals in the control of human appetite and body. Weight Pharm (Basel). 2010;3(3):748-63.

17. Toennes S, Harder S, Schramm M, Niess C. Kauert. G: Pharmacokinetics of cathinone, cathine and norephedrine after the chewing of khat leaves. $\mathrm{Br}$ J Clin Pharmacol. 2003;56:125-30.

18. John U, Hanke M, Rumpf HJ, Thyrian JR. Smoking status, cigarettes per day, and their relationship to overweight and obesity among former and current smokers in a national adult general population sample. Int J Obes Relat Metab Disord. 2005;29:1289-94.

19. Heymann TD, Bhupulan A, Zureikat NE, et al. Khat chewing delays gastric emptying of a semi-solid meal. Aliment Pharmacol Ther. 1995;9:81-3.

20. Boneva A, Boyanov M. Body composition analysis by leg-to-leg bioelectrical impedance and by dual-energy $X$-ray absorptiometry in non-obese and obese individuals. Diabetes Obes Metab. 2008;10:1012-8.

21. Jackson AS, Stanforth PR, Gagnon J, Rankinen T, Leon AS, Rao DC, Skinner JS, Bouchard C, Wilmore JH. The effect of sex, age and race on estimating percentage body fat from body mass index: the Heritage Family Study. Int J Obes Relat Metab Disord. 2002;26(6):789-96.

22. Olatunbosun ST, Kaufman JS, Bella AF. Prevalence of obesity and overweight in urban adult Nigerians. Obesity. 2011;12:233-41. 